\title{
Optimasi pembakaran menyeluruh pada reaktor pirolisis dalam menghasilkan bioarang dan asap cair
}

\author{
Kemas Ridhuan ${ }^{1 *}$, Mafruddin ${ }^{2}$, Alfi Al Rasyid ${ }^{3}$ \\ 1,2,3 Program Studi Teknik Mesin, Fakultas Teknik, Universitas Muhammadiyah Metro \\ Jl. Ki Hajar Dewantara 15 A Metro, Lampung. \\ *Corresponding author: kmsridhuan@yahoo.co.id
}

\begin{abstract}
Pyrolysis is a process of combustion in a reactor with less or no air. The results of this process in the form of bio-charcoal products, liquid smoke, tar, and sin gas. To obtain optimal bio-charcoal products and liquid smoke, it is necessary to develop a pyrolysis process by means of thorough combustion. This combustion has the advantage that the combustion fire will heat up the entire reactor wall so that it will speed up the pyrolysis process and the combustion temperature will be high so it will generate more products, especially liquid smoke. This study aims to determine combustion achievement temperatures in the combustion chamber and reactor as well as the efficiency of the results of bio-charcoal and liquid smoke obtained. This research was conducted at the Laboratory of Mechanical Engineering Universitas Muhammadiyah Metro, this study uses a pyrolysis reactor with a total combustion chamber and uses fine sand insulation. The condenser uses a 0.5-inch diameter copper pipe with 11 turns. Biomass fuels use sengon wood. The raw material of sengon wood is $10 \mathrm{~kg}$. Data from this study are compared with research data on pyrolysis reactors that have not been optimized so that the differences are known. The results obtained are the combustion temperature in the combustion chamber in the previous conditions, namely $563^{\circ} \mathrm{C}$, and the optimization conditions $651^{\circ} \mathrm{C}$, then the combustion temperature in the reactor in conditions before $370^{\circ}$ $C$ and the optimization conditions $329^{\circ} \mathrm{C}$. Liquid smoke results obtained in conditions before 0.9 liters and 1.2-liter optimization conditions. Then the results of bio-charcoal obtained in conditions before $2.0 \mathrm{~kg}$ and $2.5 \mathrm{~kg}$ optimization conditions.
\end{abstract}

Keywords: Pyrolysis, comprehensive burning, liquid smoke, bio-charcoal, optimization.

\begin{abstract}
Abstak
Pirolisis merupakan suatu proses pembakaran di dalam reaktor dengan sedikit atau tidak ada udara. Hasil proses tersebut yang berupa produk bioarang, asap cair, tar dan singas. Untuk mendapatkan produk bioarang dan asap cair yang optimal maka perlu dikembangkan proses pirolisis dengan cara pembakaran menyeluruh. Pembakaran ini memiliki keunggulan yaitu api pembakaran akan memanasi diseluruh dinding reaktor sehingga akan mempercepat proses pirolisis dan suhu pembakaran akan tinggi maka akan menghasilkan produk yang lebih banyak khususnya asap cair. Tujuan dari penelitian ini yaitu untuk mengetahui capaian suhu pembakaran di ruang bakar dan reaktor serta efisiensi hasil bioarang dan asap cair yang didapat. Penelitian ini dilakukan di Laboratorim Teknik Mesin Universitas Muhammadiyah Metro, penelitian ini menggunakan reaktor pirolisis dengan ruang bakar menyeluruh dan menggunakan isolasi pasir halus. Kondensor menggunakan pipa tembaga berdiameter 0,5 inchi dengan 11 lilitan. Bahan bakar biomasa menggunakan kayu sengon. Bahan baku kayu sengon sebanyak $10 \mathrm{~kg}$. Data hasil penelitian ini dikomparasikan dengan data hasil penelitian pada reaktor pirolisis yang belum dioptimasi, agar dikatahui perbedaannya. Hasil penelitian yang didapat yaitu suhu pembakaran di ruang bakar pada kondisi sebelum yaitu $563^{\circ} \mathrm{C}$, dan yang kondisi optimasi $651^{\circ} \mathrm{C}$, lalu suhu pembakaran di reaktor pada kondisi sebelum $370^{\circ} \mathrm{C}$ dan yang kondisi optimasi $329^{\circ} \mathrm{C}$. Hasil asap cair yang didapat pada kondisi sebelum 0,9 liter dan
\end{abstract}


yang kondisi optimasi 1,2 liter. Kemudian hasil bio-arang yang didapat pada kondisi sebelum $2,0 \mathrm{~kg}$ dan yang kondisi optimasi $2,5 \mathrm{~kg}$.

Kata kunci: Pirolisis, pembakaran menyeluruh, asap cair, bio-arang, optimasi.

\section{Pendahuluan}

Pirolisis merupakan suatu proses pemanasan suatu zat atau bahan dengan atau tanpa adanya oksigen sehingga terjadi penguraian komponen-komponen penyusunnya. Penguraian yang tidak teratur dari bahan bahan organik yang disebabkan oleh adanya pemanasan tanpa berhubungan dengan udara luar dengan suhu yang cukup tinggi sehingga akan terjadi reaksi penguraian dari senyawa-senyawa kompleks yang menyusun bahan biomassa dan menghasilkan zat dalam tiga bentuk yaitu padatan, cairan dan gas [1]. Untuk mendapatkan hasil produk pirolisis yang optimal maka diperlukan suatu unit peralatan atau reaktor yang lebih efektif dan efisien dengan bagiannya dalam memproses biomassa tersebut menjadi bioarang dan asap cair. Peralatan tersebut yaitu reaktor dan kondensor. Pada reaktor terjadi proses pembakaran pirolisis biomassa dari padatan menjadi gas panas dan dan juga menghasilkan bio-arang. Dan pada kondensor terjadi proses pendingin gas panas pembakaran menjadi cairan dan menghasilkan asap cair. Unit rangkaian tersebut merupakan satu kesatuan utuh dalam system kerja produksi pirolisis. Proses pembakaran di bagian reaktor merupakan faktor yang sangat menentukan terhadap hasil bio-arang dan asap cair yang didapatkan.

Beberapa hal yang dapat mempengaruhi proses pembakaran yaitu bahan bakar (biomassa), cara pembakaran dan bentuk reaktor/ruang bakar. Berdasarkan penelitian sebelumnya [2], bahwa suhu tertinggi pada proses pembakaran nonkarbonisasi dengan bahan kulit kelapa muda dapat mencapai suhu $430^{\circ} \mathrm{C}$. Kandungan fenol terbesar terdapat pada asap cair hasil pirolisis pada temperatur $350^{\circ} \mathrm{C}$, dan ini tidak mengurangi kwalitas proses pirolisis yang terjadi. Kandungan fenol terbesar terdapat pada asap cair hasil pirolisis pada temperatur $350^{\circ} \mathrm{C}$, dan ini tidak mengurangi kwalitas proses pirolisis yang terjadi. Menurut Wijayanti, Selain mampu mereduksi dan menghasilkan bahan bakar secara optimal pada temperatur pirolisis $300^{\circ} \mathrm{C}$, nilai kalor char yang dihasilkan secara optimal juga terjadi pada temperatur ini. Bila sebelum dipirolisis nilai kalor sampah adalah sebesar $1980 \mathrm{kcal} / \mathrm{kg}$, maka pada temperatur $300^{\circ} \mathrm{C}$ nilai kalor dapat meningkat hingga $150 \%$ dari nilai sampah [1].

Kemudian beberapa ukuran lainnya yang mempengaruhi hasil bioarang dan asap cair adalah suhu dan waktu pembakaran yang terjadi di reaktor. Semakin tinggi suhu pembakaran maka akan mendapatkan asap cair yang lebih banyak ketimbang bio-arang. Dan sebaliknya suhu pembakaran rendah akan menghasilkan bio-arang yang lebih banyak ketimbang asap cair.

Untuk waktu pembakaran di reaktor yang terjadi lebih lama maka akan menghasilkan asap cair yang banyak ketimbang bio-arang dan sebaliknya dengan waktu pembakaran yang sebentar maka akan menghasilkan bio-arang yang banyak ketimbang asap cair. Sehingga perlu diupayakan suatu cara sehingga hasilnya dapat lebih efektif dan efisien yaitu dengan suhu pembakaran yang tinggi dan waktu yang singkat.

Kemudian kecepatan pembakaran juga dapat dipengaruhi oleh struktur bahan biomassa, kadar karbon terikat, keras dan lunaknya bahan bakar meskipun secara teori jika kadar volatilnya tinggi maka akan mudah terbakar dan kecepatan pembakaran lebih tinggi. Ukuran ketebalan plat tabung pitot dapat diperkecil sehingga dapat mempercepat perpindahan panas dan dapat cepat membakar bahan sehingga waktu yang dibutuhkan untuk membakar bahan lebih sedikit. 
Untuk memenuhi ukuran besarbesaran yang diisyaratkan tersebut maka di rancang suatu reaktor pirolisis dengan pembakaran menyeluruh sebelum optimasi (Gambar 1). Reaktor ini memiliki system pembakaran secara menyeluruh di sekeliling reaktor yaitu dengan menempatkan bahan bakar biomassa pada sekeliling dinding samping dan bawah reaktor. Sehingga pemanasan dapat terjadi pada sekeliling dinding reaktor bahkan pada bagian atas reaktorpun juga terjadi pemananasan. Pemanasan seperti ini dapat meningkatkan suhu pembakaran reaktor. Menurut Davison [3], bahwa sumber panas dalam pirolisis juga mempengaruhi rendemen yang dihasilkan. Sumber panas dalam penelitiannya hanya berasal dari sisi bawah tabung sehingga panas yang diterima bahan di dalam pirolisator tidak merata.

Selain itu pada dinding ruang pembakaran reaktor ini juga diberi isolator, agar panas pembakaran yang terjadi tidak keluar, sehingga suhu pembakaran dapat lebih tinggi dan waktu pemakaran juga dapat lebih singkat. Namun ada kekurang dari reaktor ini yaitu sering terjadi kebocoran pada bagian tutup reaktor. Berdasarkan penelitian sebelumnya [4], penggunaan reaktor dengan pembakaran menyeluruh sering terjadi kebocoran pada seal/perapat tutup reaktor. Hal ini dikarenakan suluruh bagian reaktor berada di dalam ruang bakar sehingga menyebabkan terjadinya sebagian seal/perapat tutup reaktor ikut terbakar dan terjadi kebocoran. Kebocoran yang terjadi dapat menyebabkan hasil asap cair tidak maksimal. Sehingga perlu dilakukan perubahan atau modifikasi sedikit, yaitu dengan memperpendek ukuran tinggi ruang bakar sehingga tutup reaktor berada dibagian luar sehingga seal/perapat tidak ikut terbakar. Namun hal ini menyebabkan penyebaran sumber panas menjadi pada reaktor terbatas hanya sampai pada dinding bawah dan samping saja yang kemungkinan berdampak padalaju penyebaran panas pada reaktor menjadi berkurang, tapi hal ini tidak mengakibatkan terjadinya kebocoran pada tutup reaktor.

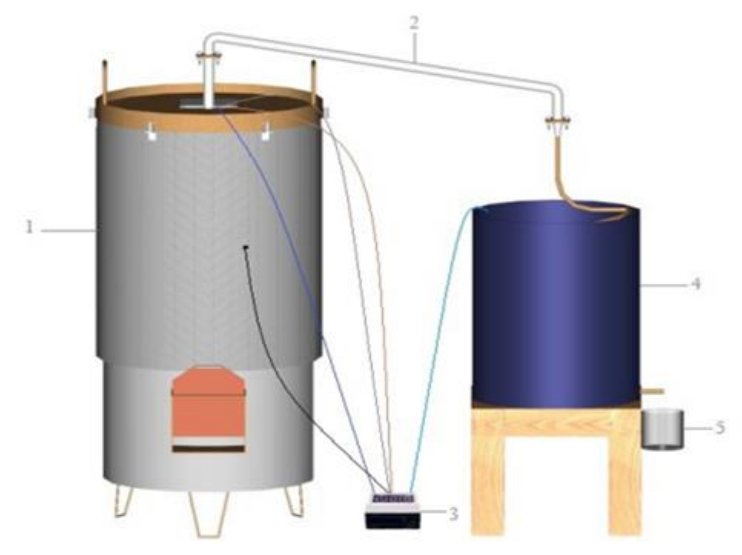

Gambar 1. Reaktor pirolisis pembakaran menyeluruh sebelum optimasi

\section{Tinjauan Pustaka}

a. Pirolisis

Pirolisis merupakan proses degradasi thermal material dalam kondisi tanpa atau sedikit adanya oksigen. Proses ini akan menyebabkan terjadinya devolatilisasi pada material hidrokarbon dalam bentuk pemutusan rantai hidrokarbon yang panjang, sehingga secara makroskopis akan menyebabkan terjadinya perubahan sifat material dari bentuk padatan ke bentuk cairan dan gas serta sedikit residu padatan yang berasal dari komponen inert di dalam material tersebut.

Menurut Syamsudin [5], bahwa selama pirolisis, biomassa mengalami reaksi primer dan reaksi sekunder yang melibatkan mekanisme perpindahan panas dan massa. Reaksi pirolisis primer berupa dekomposisi selulosa, hemiselulosa, dan lignin dalam biomassa, yang mengarah pada pembentukan produk primer dan intermediet.

Produk dari pirolisis berupa padatan (charcoal/arang), gas (fuel gas) dan cairan (bio-oil). Padatan merupakan bahan bakar bioarang, kemudian cair merupakan bahan bakar minyak (bio oil) atau cairan pengawet makanan (asap cair) kemudian gas merupakan bahan bakar gas atau singas. Semua produk hasil pirolisis tersebut sangat bermanfaat dan dapat digunakan terutama sebagai bahan bakar [6]. 
Pada proses pirolisis, temperatur reaktor bervariasi antara 300 hingga 900 ${ }^{\circ} \mathrm{C}$, namun umumnya pirolisis dilakukan pada temperatur $500-550{ }^{\circ} \mathrm{C}$ untuk menghasilkan produk cair sebagai produk utama. Secara umum material yang diberi perlakuan panas pada temperatur menengah $\left(200-300{ }^{\circ} \mathrm{C}\right)$ akan menghasilkan produk dominan dalam bentuk padat. Material yang diberi perlakuan panas pada temperatur tinggi $\left(400-600{ }^{\circ} \mathrm{C}\right)$ akan menghasilkan produk dominan cairan yang lebih banyak, sedangkan pada temperatur yang sangat tinggi $\left(>800{ }^{\circ} \mathrm{C}\right)$ produk gas merupakan produk yang dominan.

\section{b. Reaktor}

Reaktor Pirolisis merupakan suatu alat pengurai senyawa-senyawa organik yang dilakukan dengan proses pemanasan tanpa berhubungan langsung dengan udara luar dengan suhu $300-600^{\circ} \mathrm{C}$. Reaktor pirolisis dibalut dengan selimut dari bata dan tanah untuk menghindari panas keluar berlebih, memakai bahan bakar kompor minyak tanah atau gas. Menurut Hadi [7], instalasi dengan ceret dapat menghasilkan biochar dengan biaya sangat murah, efisiensi rendah, kualitas biochar rendah. Sedangkan instalasi wajan dan drum menghasilkan efisiensi tinggi, biaya murah, asap cair tidak dapat ditampung. Dan desain instalasi kombinasi drum-wajan mempunyai rendement tinggi, biaya murah, asap bisa ditampung.

c. Pembakaran menyeluruh

Pembakaran adalah suatu reaksi kimia antara bahan bakar dan pengoksidasi (udara atau oksigen) yang menghasilkan panas dan cahaya. Proses pembakaran ini dapat berlangsung jika ada: bahan bakar, pengoksidasi (udara/oksigen) dan panas atau energi aktivasi. Proses pembakaran biomassa melibatkan sejumlah aspek fisik dan kimia yang kompleks. Secara umum proses pembakaran tergantung pada propertis dari bahan bakar dan aplikasi pembakaran. Proses pembakaran ini dapat dibagi dalam beberapa proses yaitu pengeringan, pirolisis, gasifikasi dan pembakaran. Proses pembakaran dapat berlangsung secara kontinu, proses pengeringan dan pirolisis/gasifikasi merupakan tahap awal pada proses pembakaran bahan bakar padat.

Pembakaran menyeluruh merupakan suatu proses pembakaran yang memanasi diseluruh permukaan reaktor pirolisis dengan menggunakan bahan bakar padat/biomassa agar didapat suhu pembakaran yang tinggi dan waktu yang singkat. Reaktor berada di dalam ruang bakar secara penuh agar didapat pemanasan yang optimal dan waktu yang singkat. Berdasarkan penelitian sebelumnya [8], suhu pembakaran di reaktor mencapai suhu $512^{\circ} \mathrm{C}$ dengan biomassa kayu gelam dan menghasilkan 2,8 liter asap cair dan $2,5 \mathrm{~kg}$ bioarang.

Sumber panas akan mengelilingi suluruh bidang permukaan reaktor sehingga reaktor akan mengalami pemanasan yang merata di seluruh bagian dan secara cepat. Cara ini tentunya akan memerlukan bahan bakar yang banyak dan seal/perapat tutup reaktor akan cepat rusak karena terbakar sehingga akan terjadi kebocoran asap pembakaran. Untuk cara oprasional tidak terlalu rumit, sama seperti reaktor pada umumnya, mudah digunakan.

\section{d. Bioarang}

Bioarang adalah produk yang didapat dari proses karbonisasi biomassa yang terjadi direaktor. Bioarang merupakan suatu padatan berpori yang mengandung 85-95\% karbon, dihasilkan dari bahanbahan yang mengandung karbon dengan pemanasan pada suhu tinggi. Bio-arang merupakan bahan bakar arang yang dibuat dari bahan tumbu-tumbuhan dengan cara proses pirolisis dan dengan kwalitas kalori yang lebih baik dibanding arang biasa [9], mengatakan persen removal tertinggi didapat pada karbon aktif dengan zat aktivator $\mathrm{Na}_{2} \mathrm{CO}_{3} \quad 5 \%$ dengan persen removal sebesar 99,745\%. Kapasitas optimum penyerapan fenol dengan karbon aktif dari arang tempurung kelapa terbaik didapat pada karbon aktif dengan zat aktivator $\mathrm{Na}_{2} \mathrm{CO}_{3} \quad 5 \%$ dengan kapasitas 
serapan sebesar 220,751 mg fenol/gram karbon aktif.

Arang yang dihasilkan merupakan bahan bakar bioarang yang bernilai kalori tinggi ataupun digunakan sebagai karbon aktif. Berdasarkan penelitian sebelumnya [10], bioarang yang dihasilkan memiliki nilai kalor 9389,39 cal $/ \mathrm{kg}$ dari bahan biomassa kayu gelam dengan Kadar air 3,10 (\%) dan Kadar abu 56,31 (\%).Efisiensi pengarangan sebesar $52(\%)$. Bioarang ini lebih baik dibandingkan dengan bioarang yang lainnya.

e. Asap cair

Asap cair adalah produk dari proses pendinginan asap/gas yang terjadi di kondensor. Asap cair merupakan suatu cair yang berwarna kehitaman yang berasal dari biomasa seperti kayu, kulit kayu dan limbah industri biomasa lainnya melalui teknologi pirolisis. Asap cair akan terbentuk pada temperatur $\quad 400^{\circ} \mathrm{C}-550^{\circ} \mathrm{C}$. Dalam menghasilkan asap cair dipengaruhi oleh jenis biomassa, temperatur, waktu tinggal uap panas, pemisahan char/residu, dan kandungan abu. Asap cair yang dihasilkan dari proses pirolisis berwarna coklat gelap, hal tersebut dipengaruhi oleh bahan baku dan proses pirolisis cepat. Asap cair juga dapat berwarna merah kecolaktan atau hijau gelap tergantung dari adanya mikro karbon pada cairan dan komposisi kimianya. Menurut hasil sebelumnya [11], efisiensi asap cair yang dihasilkan sebesar $29 \%$ dengan $\mathrm{pH}$ 2,9 dengan warna kecoklatan bening dari bahan biomassa kayu gelam.

Asap cair yang dihasilkan merupakan bahan atau produk multiguna yang dapat digunakan untuk berbagai keperluan yaitu sebagai zat additive atau bahan pengawet makanan seperti tahu, bakso, ikan dan lainnya. Juga bisa untuk produk tertentu lainnya seperti bahan anti rayap untuk kayu, pupuk tanaman, penggumpal latek untuk karet dan bahan antiseptik. Menurut Fachraniah [12], bahwa asap cair adalah distilat asap yang merupakan campuran dari larutan dispersi asap hasil pirolisis kayu. Asap cair mengandung lebih dari 400 komponen dan memiliki fungsi sebagai penghambat perkembangan bakteri dan cukup aman sebagai pengawet alami.

\section{Metode Penelitian}

Pada penelitian ini bahan baku biomassa yang digunakan adalah kayu sengon dengan ukuran rata-rata $3 \times 3 \times 3$ $\mathrm{cm}$. dengan jumlah sebanyak $10 \mathrm{~kg}$ di dalam reaktor, dan Kondensor menggunakan pipa tembaga berdiameter 0,5 inch dengan jumlah 11 lilitan dengan pendingin air.

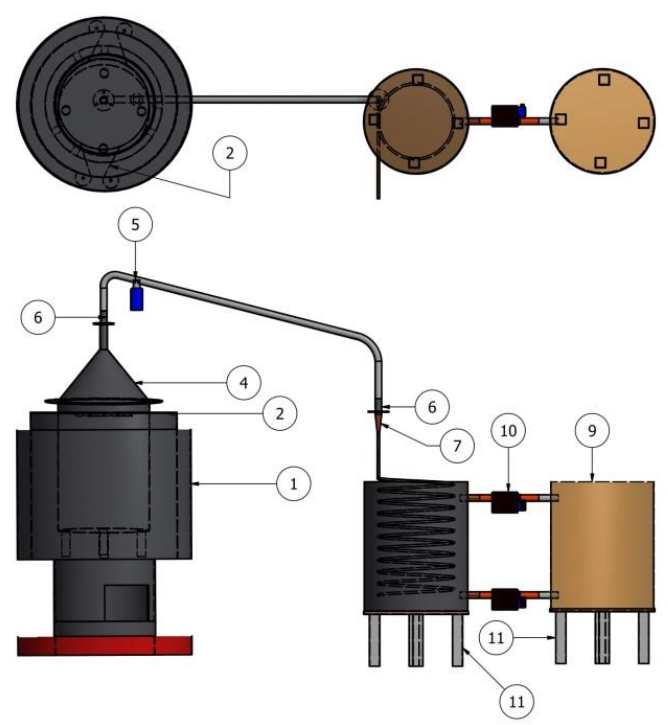

Gambar 2. Reaktor pirolisis pembakaran menyeluruh kondisi optimasi.

Keterangan Gambar 2:

1. Dinding isolasi ruang bakar

2. Ruang bakar

3. Reaktor

4. Tutup reaktor

5. Penampung tar

6. Pipa penghubung

7. Pipa kondensor

8. Kondensor

9. Tampungan air

10. Pompa air

11. Kaki tumpuan

Pengujian Pirolisis

1. Menyiapkan alat pirolisis dan bahan

2. Memasukan potongan kayu ke dalam reaktor sebanyak $10 \mathrm{~kg}$ lalu ditutup,

3. Menghubungkan reaktor dengan kondensor,

4. Mengisi air ke dalam kondensor, 
5. Memasukkan bahan bakar ke dalam ruang bakar,

6. Menyalakan bahan bakar dengan minyak tanah lalu ditutup,

7. Mencatat data suhu pada tiap titik dan jumlah asap cair sesuai waktu berjalan,

8. Memperhatikan tetesan asap cair dan nyala api sinhgas yang terjadi,

9. Mematikan api bahan bakar jika pengujian telah selesai,

10. Mendinginkan bioarang dan bereskan asap cair yang didapat lalu diukur masaa dan volumenya,

11. Melakukan pengujian dengan cara yang sama untuk variabel berbeda (biomassa).

\section{Hasil dan Pembahasan}

Setelah dilakukan pengujian pada alat pirolisis dengan pembakaran menyeluruh perubahan (optimasi) maka didapat beberapa data pengukuran suhu. Ada empat bagian titik suhu yang diukur yaitu suhu pembakaran (bahan bakar) di ruang bakar $\left(\mathrm{T}_{1}\right)$, suhu pembakaran (bahan baku) di reaktor $\left(\mathrm{T}_{2}\right)$, suhu asap/gas mau masuk kondensor $\left(\mathrm{T}_{3}\right)$ dan suhu air di kondensor $\left(\mathrm{T}_{4}\right)$.

Pada Gambar 3 terlihat bahwa perbandingan perbedaan atau penurunan suhu yang terjadi pada pengujian alat pirolisis kondisi optimasi, antara suhu di ruang bakar, suhu di reaktor dan suhu di pipa penghubung. Perbedaan suhu yang terjadi pada suhu ruang bakar dengan reaktor cukup besar dimulai pada menit ke 40 hingga ke menit 140. Peningkatan suhu pada ruang bakar terus bertambah berbanding lurus dan berimbang dengan waktu pertambahannya, hal ini dikarenakan jumlah bahan bakar terus ditambah dengan jumlah yang sama seiring bertambahnya waktu yang sama pula. Namun tidak jika dibandingkan suhu direaktor dan pipa penghubung yang tidak begitu tinggi.
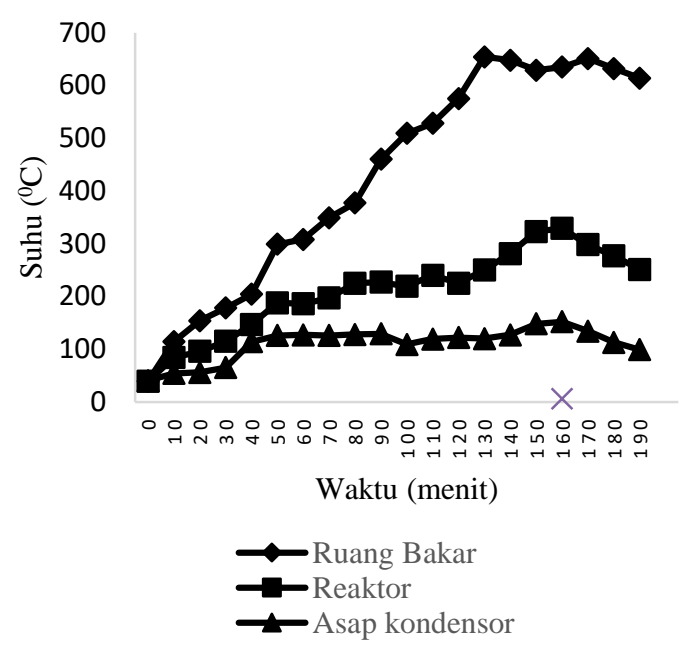

Gambar 3. Grafik perbandingan suhu yang terjadi tiap titik pengujian pembakaran optimasi.

Pada menit ke 140 nilai suhu di ruang bakar dan reaktor mulai landau, hal ini dikarenakan jumlah bahan bakar yang ada sudah terbakar semua dan tinggal sisa bara yang ada, hingga akhirnya turun dan berhenti. Perbedaan yang cukup besar terjadi dikarenakan panas yang terjadi diruang bakar tidak bisa mengalir dengan baik ke reaktor. Hal ini bisa dikarenakan plat dinding reaktor cukup tebal $(3 \mathrm{~mm})$ sehingga panas ruang bakar tidak mudah berpindah/masuk ke reaktor, sehingga suhu pembakaran bahan baku di reaktor tidak begitu besar yaitu paling tinggi $329^{\circ} \mathrm{C}$ pada menit ke 160. Juga untuk suhu asap/gas yang akan masuk ke kondensor paling tinggi $152^{\circ} \mathrm{C}$.

Berdasarkan penelitian sebelumnya [13], mengenai pembakaran menyeluruh pada ruang bakar dan reaktor pirolisis (sebelum optimasi) menggunakan bahan biomassa kayu, kemudian dibandingkan dengan hasil pengujian kondisi optimasi seperti pada (Gambar 4), terlihat bahwa ada perbedaan yang cukup jelas, ruang bakar kondisi sebelum menghasilkan suhu pembakaran yang cukup baik dari menit pertama sampai ke menit 60 yaitu $490^{\circ} \mathrm{C}$. Sementara kondisi optimasi pada saat itu masih mencapai suhu $306^{\circ} \mathrm{C}$. Hal ini dikarenakan ruang bakar kondisi sebelum, reaktornya berada didalam ruang bakar semua, sehingga panas yang terjadi dapat dengan baik mengalir ke reaktor secara 
keseluruhan dari segala sisi. Namun untuk ruang bakar kondisi optimasi peningkatan suhu cukup lambat/standar, dikarenakan laju penyebaran panasnya dari samping dan bawah saja. Dan baru mencapai puncaknya pada menit ke 130 dengan suhu tertinggi $654^{\circ} \mathrm{C}$. Walaupun suhu ini lebih tinggi dari kondisi sebelum, namun capaian suhu yang tinggi dapat terjadi dengan penambahan jumlah dan ritme bahan bakar yang lebih banyak.

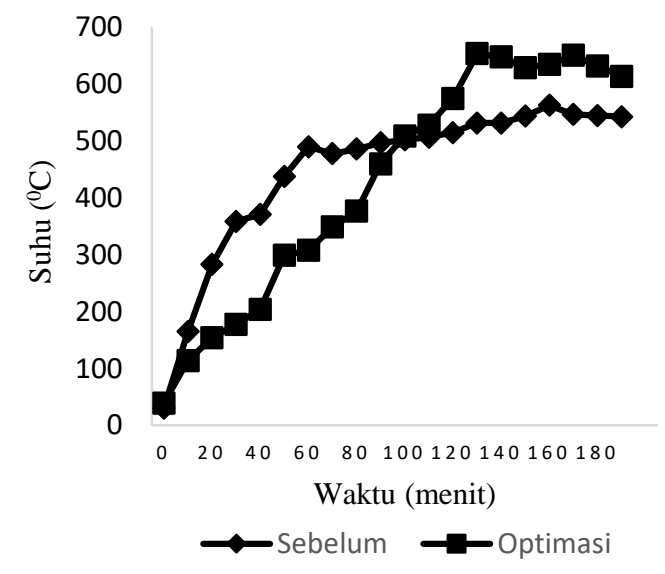

Gambar 4. Grafik perbandingan suhu pembakaran di ruang bakar sebelum dan optimasi.

Begitu juga halnya pada Gambar 5, yaitu perbandingan pembakaran pada reaktor, dimana laju peningkatan suhu yang sangat besar di awal menit untuk ruang bakar kondisi sebelum menurut penelitian sebelumnya [11], yaitu pada menit 30 suhu sudah mencapai $309^{\circ} \mathrm{C}$ hingga mencapai suhu $370^{\circ} \mathrm{C}$ dan akhirnya selesai. Laju penyebaran panas yang terjadi dari segala arah akan mempercepat terjadinya peningkatan suhu pembakaran reaktor. Dan sebaliknya dengan kondisi optimasi hanya dua sisi saja, bawah dan samping, sehingga suhu pembakaran reaktor lebih kecil yaitu $329^{\circ} \mathrm{C}$ inipun terjadi pada menit ke 150 dan pada menit ke 160 suhunya turun lagi sampai berakhir pada menit ke 190 .

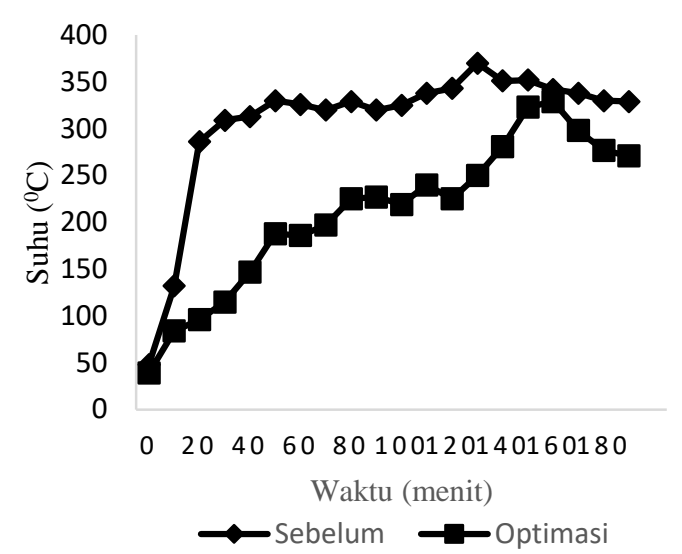

Gambar 5. Grafik perbandingan suhu pembakaran di reaktor antara sebelum dan optimasi

Dari Gambar 4 dan 5 terlihat suhu pembakaran pada kondisi sebelum lebih tinggi dibanding kondisi optimasi, namun pada kondisi sebelum karena reaktor berada didalam ruang bakar seluruhnya mengakibatkan terbakarnya seal/perapat tutup reaktor sehingga terjadilah kebocoran dan ada sebagian asap yang keluar dan ini merupakan kerugian pada asap cair yang dihasilkankan. Dan pada kondisi optimasi tidak terjadi kebocoran karena pada tutup reaktor tidak masuk ruang bakar sehingga seal/perapat tidak terbakar dan tidak bocor atau rusak.

Tabel 1. Hasil asap cair dan bio-arang

\begin{tabular}{lcc}
\hline Kondisi & $\begin{array}{c}\text { Hasil Asap } \\
\text { Cair (Liter) }\end{array}$ & $\begin{array}{c}\text { Hasil Bio- } \\
\text { arang (kg) }\end{array}$ \\
\hline Sebelum & 0,9 & 2,0 \\
\hline Optimasi & 1,2 & 2,5 \\
\hline
\end{tabular}

Pada Gambar 6 dan 7 terlihat hasil dari asap cair dan bio-arang pada kondisi optimasi lebih banyak yaitu asap cair 1,2 liter dan bio-arang 2,5 kg dibanding kondisi sebelum, yaitu 0,9 liter dan 2,0 berdasarkan hasil penelitian sebelumnya [8]. hal ini dimungkinkan karena semakin tinggi suhu pirolisis maka komponen atau senyawa yang ada di dalam biomassa akan semakin banyak yang terdekomposisi menjadi asap cair sehingga jumlah asap cair yang dihasilkan akan semakin banyak. Menurut Fadillah [14], interaksi suhu dan waktu pirolisis sangat berpengaruh nyata terhadap rendemen tar dan arang. Dan juga semakin 
tinggi suhu maka kecepatan reaksi pirolisis akan semakin meningkat sehingga kemampuan untuk menguraikan senyawa senyawa organik yang ada pada biomassa juga semakin besar. Berdasarkan Ratnawati [15], bahwa hal ini disebabkan pada suhu tinggi dan waktu yang lama dekomposisi bahan baku lebih sempurna sehingga rendemen asap cair yang dihasilkan lebih tinggi.

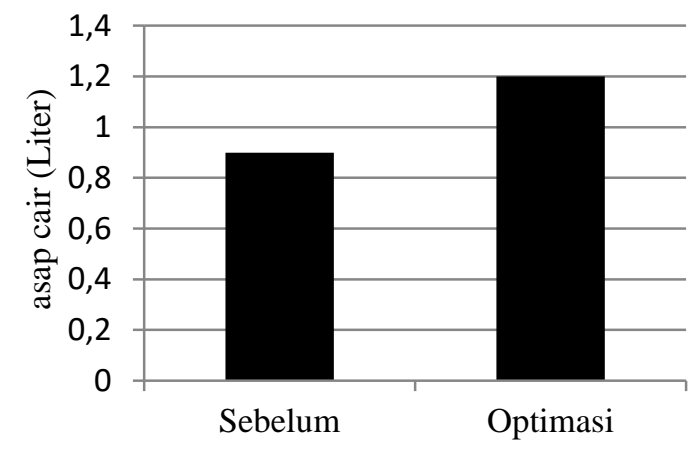

Gambar 6. Grafik perbandingan hasil Asap Cair sebelum dan optimasi

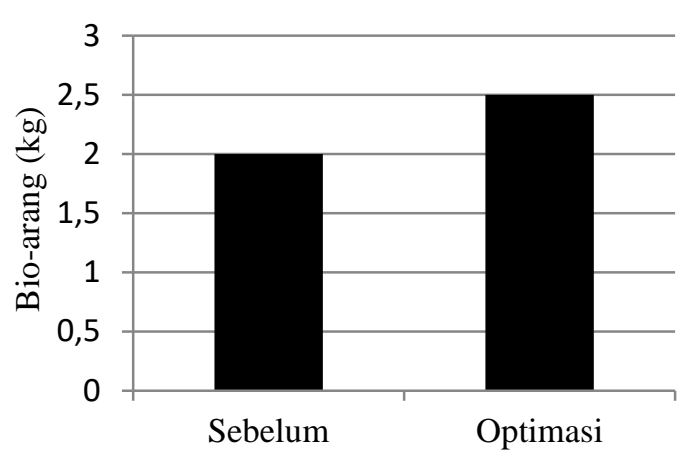

Gambar 7. Grafik perbandingan hasil Bio-arang sebelum dan optimasi

Semakin tinggi suhu pembakaran pirolisis akan menghasilkan asap cair yang lebih banyak namun untuk kondisi reaktor sebelum nasilnya lebih sedikit yaitu 0,9 liter dibandingkan kondisi reaktor optimasi yaitu 1,2 liter, hal ini dikarenakan adanya kerusakan pada seal/perapat tutup karena terbakar sehingga mengakibatkan kebocoran dan asap cair akan keluar maka ada kehilangan sehingga hasil asap cair yang keluar lewat kondensor tidak maksimal. Berdasarkan penelitian sebelumnya [16], semakin tinggi suhu dan lama waktu maka semakin banyak asap cair yang dihasilkan, efisiensi asap cair hasil tertinggi ialah pada jenis kayu rengas yaitu sebanyak $0,65 \%$ dan untuk efisiensi asap cair terendah adalah pada jenis kayu jati putih yaitu sebanyak 0,27 \%. Kemudian hasil bio-arang kondisi sebelum lebih kecil yaitu 2,0 kg dibanding kondisi optimasi yaitu 2,5 kg karena suhu yang tinggi akan mempercepat reaksi senyawa yang ada di dalam biomassa akan semakin banyak yang terdekomposisi thermal dari padatan menjadi gas/asap, sehingga jumlah padatan bio-arang mejadi lebih sedikit dan semakin banyak asap/gas yang didapat namun karena adanya kebocoran pada seal/perapat tutup reaktor maka sebagian asap tersebut keluar dan sedikit yang terkondensasi dikondensor.

\section{Kesimpulan}

Hasil kondisi optimasi ruang bakar pada alat pirolisis menunjukkan hasil yang lebih bagus atau baik dibandingkan dengan kondisi sebelum. Hasil kondisi optimasi mendapatkan suhu pembakaran ruang bakar lebih besar yaitu $651^{\circ} \mathrm{C}$ dibanding kondisi sebelum yaitu $563^{\circ} \mathrm{C}$. Suhu pembakaran reaktor pada kondisi optimasi lebih kecil yaitu $329^{\circ} \mathrm{C}$ dibandingkan kondisi sebelum yaitu $370^{\circ} \mathrm{C}$. Hasil acap cair yang didapatkan pada kondisi optimasi lebih besar yaitu 1,2 liter dibandingkan kondisi sebelum yaitu 0,9 liter. Hasil bioarang yang didapatkan pada kondisi optimasi lebih besar yaitu 2,5 kg dibandingkan kondisi sebelum yaitu $2,0 \mathrm{~kg}$.

\section{Ucapan Terima Kasih}

Ucapan terima kasih disampaikan kepada Rektor Universitas Muhammadiyah Metro dan Ketua Lembaga Penelitian dan Pengabdian (LPPM) Universitas Muhammadiyah Metro, atas bantuan dana penelitian OPR (Operasional Penelitian Rutin) tahun akademik 2020/2021.

\section{Referensii}

[1]. Wijayanti, Widya. Nur, Mega Sasongko. Dkk., 2013, Metode 
Pirolisis Untuk Penanganan Sampah Perkotaan Sebagai Penghasil Bahan Bakar Alternatif, Jurnal Rekayasa Mesin, Vol.4, No.2, ISSN 0216468X, Hlm. 85-92

[2]. Ridhuan, Kemas. Arya, Sepit. 2015. Karaktristik Pembakaran berbagai Jenis Bahan Limbah Biomassa dengan Menggunakan Proses Nonkarbonisasi. Jurnal Teknik Mesin "Turbo". Volume 4 Nomor 1. ISSN: 23016663

[3]. Devison. (2015). Rekayasa Pirolisator Berkinerja Tinggi Untuk Peningkatan Rendemen Asap Cair. Thesis Program Studi Teknologi Pertanian Universitas Andalas, Padang.

[4]. Ridhuan, Kemas,. Irawan, Dwi, 2017, Rancangan Dan Pengujian Alat Pirolisis Berbahan Bakar Dan Bahan Baku Biomassa, Prosiding Seminar Nasional Energi dan Industri Manufaktur SIGER Universitas Lampung,

[5]. Syamsudin, Sri Purwati, dkk, 2016, Pirolisis Isotermal Sludge Cake Dan Pulp Reject Pabrik Pulp Kraft, Jurnal Selulosa Vol. 6 No. 2 Desember 2016, hal. 71 sd. 82. e-ISSN: 2527 6662 p-ISSN: 2088 - 7000

[6]. Fatimah, Is. 2004, Pengaruh Laju Pemanasan Terhadap Komposisi Biofeul Hasil Pirolisis Serbuk Kayu, Jurnal Logika, Vol.1 No.1 Issn: 14102315 - Hlm.46-50.

[7]. Hadi, Abdul. Gafur, A. Udiantoro. Mukhlis, 2014, Desain Instalasi Pirolisis Limbah Pertanian Dalam Rangka Minimalisasi Emisi Gas Rumah Kaca Dari Lahan Basah, Prosiding SNST Ke-5, Fakultas Teknik Universitas Wahid Hasyim Semarang, ISBN: 978-602-99334-37. Hlm.1-9.

[8]. Ridhuan, Kemas,. Irawan, Dwi,.(2019), Comparison Of Biomass Ziolite Mixture As Catalyst On Pirolysis Combustion On Results Of Biochar And Liquid Smoke,
Prosiding Seminar Nasional Tahunan Teknik Mesin (SNTTM) XVIII,

[9]. Pambayun, Gilar S. Remigius, YEY. Rachimoellah,M. Endah,M.M. Putri, 2013, Pembuatan Karbon Aktif Dari Arang Tempurung Kelapa Dengan Aktivator Zncl2 Dan Na2co3 Sebagai Adsorben Untuk Mengurangi Kadar Fenol Dalam Air Limbah Jurnal Teknik Pomits Vol. 2, No. 1, Issn: 2337-3539, Hlm. 2301-9271.

[10]. Ridhuan, Kemas,. Irawan, Dwi,. (2019), Comparison Of Types And Size Of Biomass On Pirolysis Combustion Toward The Results Of Bio-Charcoal And Liquid Smoke The 5TH International Conference on Science, Technology and Interdisciplinary Research, IC-STAR 2019.

[11]. Ridhuan Kemas, Irawan Dwi, (2019), Proses Pembakaran Pirolisis dengan Jenis Biomassa dan Karakteristik Asap Cair yang Dihasilkan, Jurnal Teknik Mesin TURBO Vol. 8 No. 1. 2019 p-ISSN: 2301-6663, e-ISSN: 2477-250X.

[12]. Fachraniah, Fona, Z., dan Rahmi, Z., (2009), "Peningkatan Kualitas Asap Cair dengan Distilasi", Jurnal Reaksi, Vol. 7(14), pp. 1-11.

[13]. Ridhuan, Kemas,. Dwi Irawan, Dwi,. (2018), Pengaruh Jenis Biomassa Pada Pembakaran Pirolisis Terhadap Karakteristik Dan Efisiensi Bioarang - Asap Cair Yang Dihasilkan, Jurnal: Media Mesin Univ. Muh. Surakarta Volume: 20 No. 1

[14]. Fadillah, Haris,. Alfiarty, Alivia,. 2015, The Influence Of Pyrolysis Temperature And Time To The Yield And Quality of Rubber Fruit (Hevea brasiliensis) Shell Liquid Smoke, Prosiding Seminar Nasional Teknik Kimia "Kejuangan" ISSN 16934393, Yogyakarta.

[15]. Ratnawati,. Hartanto, Singgih, 2010, Pengaruh Suhu Pirolisis Cangkang Sawit Terhadap Kuantitas Dan Kualitas Asap Cair, Indonesian 
Journal Of Materials Science, Vol. 12, No. 1, Hal : 7 - 11 Issn : 14111098

[16]. Ridhuan, Kemas,. Irawan, Dwi, (2017), Rancangan Dan Pengujian Alat Pirolisis Berbahan Bakar Dan Bahan Baku Biomassa, Prosiding Seminar Nasional Energi dan Industri Manufaktur SIGER Universitas Lampung. 